Las Torres de Lucca. Revista internacional de filosofía política

ISSN-e: 2255-3827

\title{
Recelo y admisión del elemento democrático en el Leviatán de Hobbes ${ }^{1}$
}

\author{
José Luis Galimidi²
}

\begin{abstract}
Resumen. Hobbes mantiene una actitud dual respecto de la participación política en general y de la forma democrática de gobierno, que es la universalización del impulso a participar activamente en el ejercicio de la soberanía, en particular. La teoría desarrollada en el Leviatán de un lado incorpora el elemento participativo como expresión eminente de la voluntad de poder, a la vez que, del otro, trata de contener sus previsibles inconveniencias mediante una adecuada comprensión del correcto diseño y manejo de la máquina del Estado. Las críticas de Hobbes al talante democrático, que, desde una perspectiva contextualista, pueden ser consideradas como intervención ideológica antirrepublicana, también pueden ser estudiadas con provecho si se las ve como un corolario de su concepción de la naturaleza humana. La evidente contradicción de teorizar un momento inicial de máxima libertad fundadora, para luego constreñirlo a la mera aceptación de las disposiciones del gobierno absoluto, más que como inconsistencia, puede verse como lúcida aprehensión de las tensiones propias de la estatalidad barroca. Se trata, entendemos, de conciliar la preeminencia del vector de soberanía con el resguardo de la necesidad subjetiva de involucrarse en las diferentes instancias en las que se concentra y se ejerce el poder. A tal efecto, el Leviatán contempla previsiones para el fortalecimiento de la actividad económica, así como para el de la autoridad de los funcionarios públicos.
\end{abstract}

Palabras clave: Soberanía; participación; democracia; orgullo; poder.

\section{[en] Suspicion and admission of the democratic element in Hobbes's Leviathan}

\begin{abstract}
Hobbes maintains a dual attitude towards political participation in general, and the democratic form of government, which is the universalization of the participatory impulse, in particular. The theory developed in Leviathan incorporates, on the one hand, the participatory element as an eminent expression of the will to power, while, on the other, tries to contain its foreseeable inconveniences through an adequate understanding of the correct design and management of the state machinery. Hobbes's criticisms of the democratic spirit, which, from a contextualist perspective, can be considered as an anti-republican ideological intervention, can also be studied with profit if they are seen as a corollary of his conception of human nature. The evident contradiction of postulating an initial moment of maximum founding freedom, and then constraining it to the mere acceptance of the provisions of absolute government, can be seen as a lucid apprehension of the tensions of baroque statehood rather than as inconsistency. Its aim is to reconcile the preeminence of the sovereignty vector with the protection of the subjective need for participation in the different instances of the exercise of power. To this end, the Leviathan contemplates provisions for the strengthening of economic activity, as well as for the authority of public officials. Key words: Sovereignty; Participation; Democracy; Pride; Power.
\end{abstract}

Cómo citar: Galimidi, J. L. (2022). Recelo y admisión del elemento democrático en el Leviatán de Hobbes. Las Torres de Lucca. Revista internacional de filosofía política, 11(1), 89-102. https://dx.doi.org/10.5209/1tdl.77035

El "Repaso y conclusión" con que Hobbes cierra su Leviatán corrobora en el lector que lo ha acompañado en su exigente periplo la impresión de que el texto está articulado con una lógica adversativa. El discurso sobre los derechos de soberanía y sobre las correlativas libertades y responsabilidades de los ciudadanos se funda, dice Hobbes, sobre dos apoyos de índole diversa y, en más de un sentido, contrapuesta: las conocidas inclinaciones de la especie humana, de un lado, y las leyes divinas, a las que se puede acceder por revelación positiva, o por reflexión natural, del otro. Se trata de demostrar cómo es posible concebir, construir y preservar un orden colectivo que, al mismo tiempo que provee a las necesidades sociales de paz, seguridad y productividad, debe mantener su estabilidad, siempre amenazada por la desmesura de los mismos habitantes que se benefician de su existencia. Cómo pensar, es la cuestión, una convivencia social y jurídica en la que la caballerosidad y lealtad espontáneas de un Godolphin (Hobbes, 1651/1983, Un repaso y conclusión, pp. 732-733) no

Gracias a la profesora Lucía Vrljicak por su asistencia en tareas de lectura y revisión del manuscrito y de búsqueda bibliográfica.

Jose Luis Galimidi es profesor asociado de Filosofía en el Departamento de Humanidades, Universidad de San Andrés, Argentina.

Correo electrónico: galimidi@udesa.edu.ar

ORCID: https://orcic.org/0000-0001-7945-3080

3 Las referencias al Leviatán de Hobbes incluyen primero el número de capítulo y luego la página correspondiente de la edición citada. Por ejemplo,

Las Torres de Lucca. 11 (1), 2022: 89-102 
son necesariamente la norma, sino más bien la excepción. Esta forma mentis de un permanente "si bien tal cosa, se debe tener en cuenta que en cambio también tal otra" encuentra su expresión más acabada en la ambivalencia esencial de una autoridad soberana, que, a la vez que absoluta, irrevocable e incuestionable, también debe considerarse como autorizada y constituida por precisamente los mismos individuos que, ya devenidos súbditos, la temen de un modo reverente y le deben obediencia. El complejo conceptual autoridadautorizada, lindante con el oxymoron, condensa dos series de imágenes contrapuestas con las cuales Hobbes ha ido ilustrando su concepción de lo estatal a lo largo del texto. Como imagen y semejanza del Dios del Génesis que le da existencia al pronunciar su fiat, el ser humano está jerárquicamente por arriba del Estado -a la sazón, un figurado hombre artificial inmenso- en tanto es su arquitecto. Pero también se le subordina, en tanto se lo presenta alternativamente como mera matter, como súbdito de un Dios Mortal o como habitante de un edificio que lo protege contra esa miserable intemperie que es la guerra de todos contra todos. La inteligencia y la voluntad humanas, nos perplejiza Hobbes, son capaces de erigir un Leviatán, que, como príncipe de los orgullosos, debe prevalecer por sobre la vanidad ambiciosa de todos los poderes de la tierra.

Esta lógica, que asocia una teoría del caos humano con otra de su posible y legítima superación, está afectada en el Leviatán por una forma especial de ponderar los elementos y los escenarios relevantes. Subyace en Hobbes algo que podríamos llamar una desproporción esencial: las tendencias y comportamientos agresivos y avasallantes de cada persona respecto de sus semejantes no son probables en la misma medida que lo son las actitudes de racionalidad constructiva, respeto mutuo y disposición a la cooperación. Según la antropología hobbesiana, tanto la sociabilidad como la competitividad violenta son actitudes igualmente derivadas y no primitivas pero en ausencia de un poder coercitivo común, el recelo, el fraude y la anticipación del ataque son mucho más esperables que el acercamiento benevolente. Confiar en la persona equivocada puede tener consecuencias irreversibles, con pérdida de bienes, libertad o vida, mientras que desconfiar de la persona equivocada, oneroso como lo es en términos de productividad y dulzura de la existencia, no pone en riesgo inmediato la propia persistencia en el ser. Este tropismo natural hacia la competitividad y la desconfianza como actitudes más asiduas se mantiene, si bien atenuado, en la interacción de la vida civil, aunque lógicamente con otros contenidos. Por sí sola, la presencia de un poder soberano no convierte a los humanos en seres apacibles y bien intencionados. Marcas de agua de la naturaleza de la humanidad hobbesiana, como la vocación de autogobierno o el solaz en la imaginación de la propia valía y del dominio sobre los demás se suelen traducir, una vez instaurada la estatalidad, como el intento inmoderado por prevalecer y por imponer la propia voluntad, ya sea valiéndose de las estructuras del Estado o enfrentando a las autoridades designadas para su gobierno. La doctrina de Hobbes enseña que de no mediar un trabajoso y permanente proceso de pedagogía política, el desafío y, en última instancia, la rebelión son escenarios bastante más probables que la obediencia continuada y de buen grado.

Si participar políticamente es actuar desde el interior de las esferas superiores de la estructura estatal o, desde afuera, con miras a influir decisivamente sobre ellas, Hobbes, teniendo en cuenta el esquema anterior, no puede sino animar una actitud acordemente dual respecto de la participación en general, y de la forma democrática de gobierno en particular. A estar con nuestra hipótesis de lectura, la teoría política desarrollada en el Leviatán (1651/1983) debería, de un lado, poder incorporar la tendencia a la participación política como expresión eminente de la universal búsqueda permanente de poder, a la vez que, del otro, debería también tratar de contener sus previsibles desbordes mediante una adecuada comprensión del correcto diseño y manejo de la estructura estatal.

La notable amplitud del arco hermenéutico de los estudios hobbesianos da cuenta de la complejidad que caracteriza a la doctrina que nos ocupa. Por una parte, están quienes ponen el acento sobre el decidido cariz antirrepublicano de la escritura de Hobbes. Al dar preeminencia al poderío simbólico del momento soberano, el filósofo se resiste a valorizar la libertad del ciudadano que se orienta hacia la vida pública y prioriza la función estatal de su protección como mera abstención de intromisión en los asuntos del súbdito, mientras que este se atenga a la búsqueda legal de fines privados (Pocock, 1971; Skinner, 2008; Pettit, 2008). En cierto modo afín a esta perspectiva de un Hobbes antirrepublicano también se pueden mencionar los estudios que resaltan en sus textos la reivindicación de un talante decididamente despótico (Tarlton, 1978; Wolin 1990). Por otra parte, con una orientación que es contraria a la anterior, están las lecturas que coinciden en destacar el cuidado con el que Hobbes intenta preservar a la soberanía del riesgo de resistencia y rebelión que propiciaría un ejercicio del poder excesiva e innecesariamente autoritario. Y entonces, junto con las interpretaciones que resaltan los límites más o menos entrelineados que la presencia fundante del derecho natural plantea a la voluntad gubernamental (Strauss, 1936; Foisneau, 2000), deben considerarse las que ven en el afán hobbesiano por deconstruir ciertas libertades y autonomías, expresadas corporativa y parlamentariamente, y vistas por el filósofo como ecos del señorío tradicional, un claro precedente para la construcción de un Rule of Law igualitario, democrático y moderno (Dyzenhaus, 2001; Viux, 2012; Kapust y Turner, 2013; Jakonen, 2016). Desde comienzos de este siglo, aproximadamente, se han venido sumando lecturas que avanzan sobre esta dirección, y que partiendo de la necesariedad conceptual del momento voluntario de consentimiento universal, encuentran en la escritura

Hobbes 1651/1983, 11, p. 203 corresponde a la página 203 del capítulo 11. 
hobbesiana indicios favorables a una defensa de la democracia radical (Collins, 2005; Martel, 2007; Tuck, 2006, 2015). Confrontan esta postura estudiosos que estiman que el gesto teórico de construir lo estatal a partir del derecho natural del individuo y de la postulación de la antecedencia de la potentia respecto de la potestas no puede leerse sin más como encomio y legitimación de la presencia en acto del poder popular, sino más bien como advertencia crítica (Hoekstra, 2006; Lund, 2003). Finalmente, mencionemos las perspectivas que, más allá de sus diferencias, ven en Hobbes la intención de escribir modélicamente, haciendo un esfuerzo conceptual por incluir y conciliar en un proyecto ideal tendencias antropológicas y prescripciones iusnaturales de sentidos y efectos divergentes y hasta contrarios, sin que esto vaya en detrimento de su probable afán por intervenir en la disputa política de su tiempo (Crepell, 2003; Tuck, 2004; Runciman, 2012; Stauffer 2018; Field, 2020).

El presente trabajo se acerca a esta última perspectiva. Sigue las indicaciones del propio Hobbes que a menudo muestra el espíritu democratizador como expresión de la serie potencialmente desestabilizante pasiónvanagloria-felicidad-búsqueda de poder y trata de entender cómo, a la vez que el filósofo asume dicho espíritu como un apriori de la estatalidad en cuanto tal, también intenta ofrecer un modelo integrador que dé cuenta de, y, a la vez, muestre cómo enfrentar, las infirmities que no pueden dejar de aquejar a todo edificio político, cualquiera su origen y forma de gobierno. Después de repasar los aspectos de Leviatán que permiten vincular la lógica de la estatalidad con la condición radicalmente carente de la naturaleza del hombre, se analizan las razones por las que Hobbes recela de la asamblea popular como forma conveniente de gobernar la república. En el tercer apartado, finalmente, se propone una hipótesis acerca de la manera en la que el filósofo intenta conservar en su modelo ético-político vestigios del elemento democrático que es propio de la ficción del contrato originario, a la vez que debe reconocer la imposibilidad conceptual de que las repúblicas hayan podido comenzar efectivamente por vía de la institución. Digamos, por último, que para pensar cómo la teoría de Hobbes incluye e intenta limitar el afán participativo, y, sin perjuicio de las continuidades respecto de Elementos del Derecho y Del Ciudadano, nos circunscribimos aquí a una lectura del Leviatán. No sólo por una cuestión de espacio, sino también por la novedad decisiva de la teoría de la representación desplegada en el Capítulo 16. Para ello, nos apoyamos en estudios, que, por diferentes razones conceptuales y no sólo contextuales, resaltan la especificidad de esta última obra (Sorell, 2004; Tuck, 2004; Slomp, 2007; Runciman, 2012; Douglass, 2018).

\section{Finitud e institucionalidad}

La igualdad natural de todos los seres humanos que Hobbes postula como corazón de su filosofía política en el Capítulo 13 del Leviatán es una tesis de estirpe onto-teológica. Con inequívocas resonancias bíblicas, Hobbes afirma que la condición humana está afectada por una carencia radical de doble aspecto. Por una parte, el polvo con el que han sido hechos y al que volverán nuestros cuerpos nos vuelve seres sumamente vulnerables (Génesis 2:7 y 3:19, Desclée de Brouwer, 1975). Por eso, aún la persona más débil tiene fuerza física suficiente como para matar a la más fuerte, si la sorprende adecuadamente desprevenida. En correlación con esta vulnerabilidad física hay una esencial falla espiritual. La misma soberbia que ha sido capaz de renegar de la superioridad de lo divino es la que distorsiona la percepción de sí y de los demás, dando lugar a que, según la ocasión, tanto seamos propensos a imaginarnos por encima de todos cuanto a ponernos por debajo de cualquiera. Cuando no existe un poder estatal consentido en común, la consecuencia de esta igualdad natural en cuanto a la debilidad corporal y a la vanidad es la célebre condición de enemistad universal (Hobbes, 1651/1983, 13, pp. 221-222).

La tesis de la insociabilidad está presentada como culminación de una serie considerable de desarrollos correspondientes a la faz descriptiva de la Parte Primera del texto. Es razonable entender dicha tesis, entonces, como afirmando que en última instancia, y al solo efecto de comprender las complejidades propias de la materia prima con la que se ha de construir el artificio estatal, hay que asumir que, por fuera del espacio normado por la autoridad civil, el clima siempre es propicio para la aparición recurrente de situaciones tormentosas, en las que toda persona haría bien en considerar a toda otra semejante como probable enemiga. La lectura de esta especie de síntesis teoremática se enriquece si tenemos en cuenta que, en rigor, está recibiendo la carga de todo lo previamente argumentado acerca de las facultades y necesidades elementales de los seres humanos y de sus diferentes modos de interacción. En efecto, es obvio correlato directo de la afirmación del Capítulo 11, según la cual hay en toda la humanidad una perpetua e insaciable inclinación a perseguir poder tras poder que sólo cesa con la muerte. El poder de una persona, define Hobbes, es su disposición actual de recursos para intentar alcanzar una situación que se le aparece como buena o útil. Pero esta dotación de recursos, que pueden ser naturales, como ciertas destrezas innatas, o instrumentales, en el sentido de externos, como el prestigio, los amigos y aliados, la estirpe, la fortuna, etc., nunca resulta suficiente para garantizar la tranquilidad de un ser racional y deseante. En primer lugar, porque cada persona en un momento determinado no quiere solamente conseguir lo deseado, sino que también y especialmente quiere tener la seguridad de que podrá mantenerlo o volver a obtenerlo cada vez que así le apetezca. Y, en segundo y decisivo lugar, porque el poder instrumental, que es el más relevante en un contexto de interacción con otros semejantes, siempre depende de una manera u otra de opiniones, temores y deseos de otras personas, los cuales suelen ser muy inconstantes (Hobbes, 
1651/1983, 10, p. 191). En una espiral ascendente, se necesita poder en primer grado para obtener bienes y para conservarlos, y, en segundo grado, para defender y acrecentar el poder antedicho (Hobbes, 1651/1983, 11, pp. 199-200). Nadie nunca, es la hiperbólica deducción que está sugiriendo Hobbes, puede tener la certeza de que en el futuro habrá de conseguir y de conservar lo que en el instante presente piensa que le resultará benéfico o placentero o que lo preservará de situaciones desagradables o peligrosas. Incluso a los monarcas, que son las personas más poderosas, se las ve involucradas en una búsqueda incesante de dominio y de gloria (Hobbes, 1651/1983, 11, p. 200). El poder, para decirlo en términos de Walzer (1993), es un bien intrínsecamente competitivo y, por tanto, escaso. Dejar de necesitar y de disputar poder equivale a dejar de desear, lo que, para Hobbes, sólo sucede después de la muerte física. ${ }^{4}$

Esta dinámica del poder tiene su contracorriente. Se trata de las maneras. Para que alguien sea poderoso en términos de alianzas, prestigio o lealtades, es lógicamente necesario que algunas otras personas estén dispuestas a reconocer en público su valía, y a esperar su ayuda a cambio de dicho reconocimiento. Los seres humanos, explica Hobbes, a la par de la tendencia a la expansión de nuestra voluntad dominante, también tenemos un impulso opuesto y complementario, que consiste en un indeterminado, pero profundo, deseo de tranquilidad. Para poder disfrutar de ciertos placeres de la existencia, como una serena intimidad, la quietud del estudio, o el cultivo de nuestra industriosidad, necesitamos que alguien más poderoso que nosotros provea a la seguridad de nuestros cuerpos y bienes. Se llaman maneras (manners), precisamente, aquellas cualidades del carácter que inclinan a una persona a deponer buena parte de su búsqueda competitiva de poderío, moderando las expectativas de felicidad, y a obedecer a quien le ofrezca visos de protección (Hobbes, 1651/1983, 11, p. 200). En la combinación de los dos modos básicos de la interacción, según el poder o según las maneras, aparece la desproporción que mencionábamos en la presentación de estas notas. El poder de cada persona sobre las cosas y sobre sus semejantes, así como el conocimiento de las causas que le permitirían tener un cierto control sobre lo que la daña o le hace falta, son irremediablemente más limitados de lo que estima que sería necesario para su tranquilidad. La condición esencialmente carente de los seres humanos carga su percepción del futuro con una dosis de angustia insoportable. Por este motivo, la mayoría de las personas, propone Hobbes, es proclive a ofrecer su ingenua credulidad y a conceder autoridad a quien tenga la audacia y el talento retórico suficiente como para prometerles su protección. Por otra parte, nunca faltan algunas personas vanamente convencidas de la eminencia de la propia prudencia, sabiduría, o, inclusive, santidad. Usualmente, los pocos persuaden sobre la propia valía a los muchos haciendo que estos tomen por buenas sus autofantasías, incluyendo en ellas errores, exageraciones y puntos ciegos (Hobbes 1651/1983, 11, p. 203). ${ }^{5}$

Se dan, entonces, ocasionales configuraciones en las que la angustia crédula de algunos contribuye al poder de otros, habitualmente más inescrupulosos que bienintencionados. En algún momento, dichos esquemas de poder se pueden consolidar con la estructura de la religión. Ante lo intolerable de la incertidumbre que provoca el saberse a merced de múltiples eventos imposibles de comprender y de anticipar, y que pueden llegar a ser muy dolorosos, es natural que los seres humanos fuguen hacia lo imaginario, fantaseando la existencia de poderes invisibles que causan dichos eventos, y que son capaces de agraciarlos o dañarlos a voluntad. Desde un punto de vista puramente sociológico, Hobbes explica que la religión puede verse, precisamente, como un dispositivo artificial de contención y control social mediante el cual algunas personas dotadas de un talento retórico, inventiva y ambición de poder excepcionales se presentan ante las personas del común como enviados e intérpretes de aquellos poderes invisibles. Son portadores de promesas de beneficios y protección a cambio del cumplimiento de ciertas normas de comportamiento y de culto (Hobbes, 1651/1983, 11, pp. 206-207, 12, p. 208). Considerando esa estructura en la que hay una confluencia de miradas anhelantes en busca de protección y donde se atribuye poder ordenador a las personas que ejercen la mediación entre lo más alto y el ámbito horizontal de la convivencia cotidiana, puede decirse que la escena religiosa guarda una relación de isomorfía con la del Estado hobbesiano y en la economía argumentativa del Leviatán, puede ser ubicada como eminente ratio cognoscendi del poder político pacificador y secular.

A propósito de lo anterior, digamos entonces que, en términos descriptivos, Hobbes define al Estado como una configuración de poder que, al ser eminente en dos aspectos que son correspondientes, resulta única entre todos los modos artificiales de asociación humana (Hobbes, 1651/1983, 10, p. 189). El Common-wealth debe,

En el Capítulo 6, Hobbes señala que los hombres llaman felicidad al éxito continuo en obtener lo que se desea. Pero la dinámica misma del deseo muestra que toda vez que se satisface un anhelo, surgen otros nuevos, lo cual impide toda vivencia de un estado de reposo. Asimismo, tal como leemos en el Capítulo 11, el individuo busca no solo el éxito, esto es conseguir lo deseado, sino asegurar lo conseguido y el camino para alcanzar sus deseos futuros, lo que requiere a su vez adquirir más poder. Por ello, en oposición a la tradición antigua y escolástica, lo que el individuo busca de manera incesante, según Hobbes, es poder y no, más bien, la felicidad como fin último de todas sus acciones. La búsqueda de felicidad, en otras palabras, es el nombre que Hobbes da a esa dinámica infinita del deseo y del poder para satisfacer anhelos presentes y futuros y asegurar los ya alcanzados. Un proceso continuo que, al mismo tiempo, incorpora dentro de sí elementos de intranquilidad ligados a la capacidad de previsión de los seres humanos como agentes racionales. Para un estudio reciente acerca de las paradójicas sensaciones de miedo y ansiedad implicadas por la concepción hobbesiana de la felicidad, véase Airaksinen (2019).

Gabriella Slomp, justamente, propone el afán de gloria como punto arquimédico para la comprensión de toda la dinámica de las relaciones interpersonales en Hobbes. Al mismo tiempo, señala que la diferencia de Leviatán respecto de los tratados anteriores reside en que dicho impulso no afecta a todos los individuos por igual, sino que energiza a unos relativamente pocos, que son quienes, en definitiva, dan el tono general al clima político de una situación concreta (Slomp, 2007). 
por un lado, proveer a la mayor articulación de bienes terrenales que es posible concebir, puesto que apunta a consolidar la paz interior, la convivencia colaborativa y confortable y la defensa común contra enemigos externos. Y a tal fin, por otro lado, debe contar, consecuentemente, con la mayor acumulación de fuerzas que sea posible coordinar bajo una única voluntad, nutrida por el aporte de todos los habitantes del territorio involucrado. Pero para lograr el salto de calidad que haga del Estado el mayor y más estable poder de factura humana sobre la tierra, se debe interpelar a todos los interesados en su existencia con referencias que consten de una manera más palpable y cercana que la que era del caso en el fenómeno religioso. El poderío -visible y concreto- de la república soberana se establece, según la teoría de Hobbes, a partir de la participación voluntaria de cada uno, en primera persona del singular, contribuyendo con fuerzas y recursos propios y asumiendo junto con cada uno de los demás conciudadanos un compromiso irrevocable de autorización (Hobbes, 1651/1983, 17, p. 267). De este modo, la eminencia de poderío fáctico que caracteriza al Estado se asienta, en verdad, sobre una dimensión que es propiamente política y deontológica. En primer lugar, porque la teoría ha investido la voluntad antropológica de poder de cada particular con la dignidad del derecho natural. La ambición de dominio sobre los demás, da a entender Hobbes en el Capítulo 14, no es solamente un impulso psicológico, sino que también expresa una potestad legítima en todo ser humano que no se haya comprometido voluntariamente a limitar su libertad natural (Hobbes, 1651/1983, 14, pp. 227-228). Y, paralelamente, porque cuenta con que la necesidad de tranquilidad y de confort ha sido elevada al rango de ley racional de la naturaleza, que, en su rasgo más general, es la que prescribe la intención de actualizar in foro externo los impulsos respetuosos y colaborativos. Una persona que cumple pactos, lima asperezas, es agradecida, depone la arrogancia y el orgullo, etc., está dando a entender con claridad que se inclina por un modo pacífico de existencia, según indican las maneras. El Estado de Hobbes, así, se constituye sobre la doble base de una autorrestricción de derechos, no solo de ambiciones, y provee a una necesidad que también es un mandato moral. ${ }^{6}$

Hay, entonces, un talante decididamente iluminista en la propuesta política de Hobbes, ya que remite la consistencia y legitimidad de la objetividad institucional al acuerdo ético que se le presta en la intimidad subjetiva de la conciencia. El Estado es artificial, pero su estructura no es azarosa ni arbitraria. Por el contrario, tiene un conjunto de notas que son esenciales a su naturaleza (Hobbes, 1651/1983, Introducción, p. 118, 17, p. 267,29 , p. 395) y su conservación y fortaleza dependen directamente del grado en que sus gobernantes y súbditos entiendan y quieran llevar a la práctica los principios que lo constituyen. Hobbes no es un utilitarista de vuelo rasante. La existencia y persistencia del orden estatal dependen, en su concepción, del acuerdo de un número crítico de voluntades que hayan alcanzado cada una un grado mínimo de racionalidad instrumental y que, en su fuero interno, hayan asumido como efectivamente acaecido el compromiso recíproco que las obliga, moralmente, a honrar los pactos de obediencia al poder común y de respeto mutuo (Taylor, 1965; Warrender, 1957; Dotti, 1989; LLoyd, 1992; Stauffer, 2018). El Estado de Hobbes es un dispositivo que reordena, desde una perspectiva más abarcativa, las diferentes configuraciones, inestables por sí solas, que puedan generarse a partir de las dinámicas del poder y las maneras. La república-Leviatán es un artificio que, con vocación de eternidad, o, al menos, de estabilidad a largo plazo, está diseñado para diluir, dentro de lo posible, la visión de los escenarios amenazantes que angustian la imaginación de los seres humanos, que se saben o intuyen muy vanidosos y vulnerables, así como para contribuir a la búsqueda sensata de una cierta felicidad de cada uno de sus integrantes. ${ }^{7}$ Un artificio legítimo de poder, construido en común, que provee a la condición existencialmente desvalida de cada persona.

\section{Excesos archeotrópicos}

En la perspectiva de Hobbes, la instauración colectivamente convenida del poder público que protege los intereses privados de cada uno y que en cierto modo consolida la primacía de lo racional sobre lo pasional no es algo que se pueda dar por establecido de una vez y para siempre. La asociación estatal nunca está exenta de la amenaza del deterioro y del retorno al "caos originario" (recurrente referencia al momento teológico de creación del mundo) de violencia y guerra civil (Hobbes, 1651/1983, 36, p. 498). En lo que nos ocupa, que es la cuestión de la participación democrática, podemos decir que la finitud radical que afecta a la condición humana aparece, una vez instaurada la convivencia civil, bajo la figura del ambicioso que tiene como objeto eminente

\footnotetext{
Para una elaboración reciente, e intelectualmente desafiante, que ve la ética de Hobbes como una conciliación de normativas orientadas a la vez hacia el bien del agente y hacia el deber para con los demás, cf. Abizadeh (2018).

La proyección de la búsqueda subjetiva de felicidad hacia la concepción del orden institucional de la teoría de Hobbes ha recibido enfoques diversos. Mencionamos, a modo de ilustración, la visión de Rutherford (2003), para quien es deber del soberano hobbesiano el asegurar a los ciudadanos los medios para perseguir su felicidad, que les permitan mantener las expectativas subjetivas de una buena vida, al tiempo que limitar la búsqueda incesante de poderío. En términos de este autor, un viraje de plena "felicity" a un moderado "contentement". Foisneau (2014), por su parte, señala que la búsqueda de la felicidad implica la preocupación perpetua por adquirir poder, un proceso puramente acumulativo que no conoce ningún fin final. Para Hobbes, la búsqueda de poder reemplaza así la búsqueda de felicidad y entonces, en la medida en que la filosofía moral es lo que limita el deseo individual de poder, ninguna noción de felicidad puede formar parte de ella, ni tampoco, por tanto, ser concepto relevante para la comprensión de los propósitos estatales.
} 
de su deseo los recursos del poder estatal. Es propio del orgulloso irredento, dice Hobbes, ofenderse por la falta de correspondencia que suele haber entre su desmedida autoestima y el poco o nulo reconocimiento a su sabiduría que le demuestra el poder soberano en forma de cargos de alta responsabilidad. (Hobbes, 1651/1983, 11, p. 202). De modo espejado, tampoco es raro que la persona simple y apocada, propensa a preferir el estilo actitudinal de las manners, tienda a dejarse conducir por quien le habla fuerte, desprecia a las autoridades establecidas y promete, a cambio de lealtad, mucho más que lo que estas están ofreciendo. Para empeorar las cosas, a menudo, señala el filósofo, la codicia y la vanidad desmedidas se presentan como engañoso indicio de magnanimidad. En cualquier caso, ambos tipos, el orgulloso y el sumiso, son constitutivamente proclives a "olvidar" el compromiso ficto de autorización y obediencia, que ha de ser asumido como real por el solo hecho de vivir en un espacio políticamente ordenado. Con una actitud que es propia del necio del Capítulo 15, ambos tienden, cada uno a su manera, a desentenderse del efecto desestabilizante que provocaría su retaceo al pleno acuerdo y aporte a lo común que son condición constitutiva del poder soberano absoluto. Este tipo de consideraciones ofrece, a grandes rasgos, las bases del recelo recurrente que muestra Hobbes en Leviatán por el elemento democrático, o, dicho en forma inversa, de su preferencia por el talante monárquico. Repasemos algunos de los tópicos que menciona el texto en tal sentido.

\section{Los intereses}

El lugar natural desde el cual ordenar la lógica que enhebra las múltiples ocasiones en las que Hobbes expresa sus reservas para con lo democrático es el Capítulo 19 de Leviatán, "De las diferentes clases de república por institución y de la sucesión al poder soberano." Allí se explica que puede haber tres clases de repúblicas, según sea que el oficio soberano representativo está ejercido por una persona natural, o por una asamblea, integrable ésta, a su vez por varias, o por todas las personas adultas que constituyen la asociación política. En un primer momento, Hobbes presenta monarquía, aristocracia y gobierno popular como formas equivalentes en cuanto a dignidad, poder y atribuciones. Y a esto pueden confluir varios motivos. Por una parte, el momento instituyente de una república cuenta, teóricamente, con la asistencia de todas las voluntades involucradas. Y éstas, al hallarse todavía por hipótesis en condición de naturaleza, no se deben, en derecho, a ningún compromiso previo con otras personas, naturales o artificiales. Dado que la institución es un momento nomotético de encuentro entre libres e iguales, no puede haber allí ningún criterio objetivo desde el cual calificar como buena o mala la decisión por una u otra de las opciones lógicamente disponibles. Por otra parte, el tratamiento del tópico es una buena oportunidad para reivindicar el principio moderno de soberanía y confrontar así con el paradigma clásico aristotélico en su mismo terreno (Dotti, 2014). Afirmar la igual legitimidad de las tres formas posibles es una manera de resaltar la primacía del momento artificial y voluntario en lo político. Llamar despotismo a una monarquía, oligarquía a una aristocracia, o anarquía a una democracia, advierte Hobbes, no es un modo conceptualmente adecuado de referirse a variantes supuestamente defectuosas, sino más bien una expresión del inadecuado desagrado que siente en general la persona que así se expresa por el mero hecho de tener que ser gobernada.

Sin embargo, tal como venimos sosteniendo, Hobbes es especialmente insistente en señalar que la antropología, por decirlo de alguna manera, pesa. Esto se ve cuando, al analizar las diferencias que existen entre las diversas formas de república, el pensador desliza algunas desventajas comparativas de la democracia respecto de la monarquía. Un primer problema, señalado por Hobbes, es el de la distancia que existe entre los respectivos intereses de las personas naturales que fungen en situación soberana, y los de la persona artificial, cuya carga aquéllas han asumido voluntariamente. Hobbes postula que los intereses públicos nunca pueden equiparar la intensidad con la que cada persona natural registra sus prioridades privadas, más cercanas, por así decir, a su self más íntimo, principio último de la acción voluntaria individual. En el caso de los integrantes de una asamblea popular soberana, es esperable, dada la teorizada naturaleza humana, que, si se presenta la ocasión, cada uno de ellos se incline por ofrecer un consejo perjudicial para la causa pública, o por la traición y hasta por la guerra civil, si es que, en sus cálculos, ello puede ofrecerle mayores oportunidades de aumentar su fortuna, su prestigio o su poderío individual que las que le daría optar por una mejoría de la tranquilidad y prosperidad comunes. Por el contrario, en el caso de un monarca, la distancia entre los intereses de la persona pública que porta él exclusivamente y los de su persona natural privada en lo que hace a riqueza, honores y seguridad casi que es nula. Un rey, dice Hobbes, se nutre, se vale y se gloria de la riqueza y poderío de su reino, y esto liga su suerte personal, y, no menos importante, la consideración de la propia valía, a la de sus súbditos tomados en conjunto (Hobbes, 1651/1983, 19, pp. 280-281).

Interesa observar aquí que Hobbes está sugiriendo una clara diferencia en cuanto a la altitud y sensatez de las respectivas miras adoptadas por quienes portan una y otra forma de república. A cambio de un mero beneficio económico, o de vanidad, el asambleísta popular paradigmático (de Hobbes) parece dispuesto a arriesgarse a ser desacreditado por haber sugerido un consejo que resulte perjudicial, o a ser descubierto y ejecutado por haber incurrido en traición. Y, lo que es infinitamente más serio, sería capaz de preferir la guerra civil, que es sinónimo de miseria para todos sus conciudadanos y para sí mismo, si imaginara con ello alguna posibilidad de éxito personal. Literalmente, el particular que integra una asamblea soberana estaría dispuesto, 
según Hobbes, a incurrir en la contradicción de valerse de un cargo supremo en el Estado para propiciar su destrucción. El monarca, en cambio, si bien comparte con todos sus congéneres el interés por su bienestar económico personal, tiene, además, por motivos egoístas, una preocupación por la seguridad y la honorabilidad de todos. El mismo afán de gloria y de dominio que incentiva el cumplimiento cabal de su responsabilidad en el monarca es el que fomenta, sería el corolario, la ambición desestabilizante de las elites que bregan por la hegemonía en una asamblea democrática (Slomp, 2007; Field, 2020). Y a esto se suma la dimensión ética. Las leyes civiles no pueden tener jurisdicción positiva sobre quienes ejercen el poder de soberanía; pero sí la tienen, moral, las leyes de naturaleza, en tanto que todas las personas racionales siguen siendo súbditos del reino natural de Dios (Hobbes, 1651/1983, 26, p. 347). Pues bien, Hobbes parece pensar que la fuerza y nitidez con que se percibe la responsabilidad para con las leyes de la naturaleza es proporcional al grado de incidencia legítima de la propia voluntad en lo que finalmente será una acción que actualice la voluntad del conjunto. El filósofo sugiere que un exceso de mediaciones (y, por tanto, de ficciones constitutivas) institucionales puede sobreexigir, y, en el límite, hacer colapsar, la capacidad de autolimitación que deben asumir las personas que acceden presencialmente a un ámbito de poder.

\section{La inconstancia}

Otro aspecto a tener en cuenta respecto de las inconveniencias que Hobbes advierte en la democracia es el de la inconstancia. La condición de naturaleza es miserable, entre otras cosas, porque más allá del temor a este o aquel tipo de dolor, y de la aversión por esta o aquella persona concreta, dicha situación implica para todos un escenario de incertidumbre y angustia. Como se lee en el Capítulo 13, el clima de guerra de todos contra todos es un tiempo en el que no se puede fijar el deseo en nada que no sea defensivo; por ejemplo, no se puede sembrar esta temporada confiando en poder cosechar, vender, ahorrar y comerciar en ultramar en la venidera. Es tanto el desorden presente que genera la percepción de un futuro cercano incierto que ni siquiera se confía en que habrá medición concertada del tiempo (Hobbes, 1651/1983, 13, p. 224). Si el poder de alguien consiste en su disposición presente de recursos con vistas a la obtención futura de algún bien, el estado hobbesiano de naturaleza, implica, virtualmente, la anulación de todo poder. El Estado, venimos diciendo, viene a remediar lo más brutal de esta intemperie. Es un artificio que trata no sólo de dejar al enemigo afuera, sino también de reproducir en el interior del territorio algo afín, dentro de lo humanamente posible, al cosmos natural, con sus paisajes a cultivar, sus ciclos y su regularidad previsible (Hobbes 1651/1983, 17, pp. 266-267). A eso apunta, precisamente, un buen cuerpo de leyes. Una manera de asegurar que cada persona sepa a qué criterios públicos de justicia y de comportamiento correcto con las demás debe atenerse.

Pero claro, está la cuestión del alma artificial que dirige la maquinaria estatal, que es la voluntad soberana. Si en general todo poder está al servicio de lo que una voluntad con imaginación delibera y determina como bueno para sí, el alma soberana tiene la misión de determinar lo que es bueno para lo público, y disponer sus recursos a tal fin. Esa es su esencia; para ello ha sido investida y autorizada (Hobbes, 1651/1983, 17, p. 267). Y el problema, entonces, radica en que ella misma, al estar compuesta en última instancia por una o por muchas voluntades naturales, también introduce, paradójicamente, un factor de inconstancia precisamente allí donde debería contenerla. La voluntad humana, por naturaleza, es inconstante, varía de persona en persona, según carácter, constitución y biografía, y, en un mismo individuo, también de momento en momento, en función de los diversos elementos que configuran su mundo interior, pasional y cognitivo, así como la evaluación de la circunstancia externa (Hobbes, 1651/1983, 6, p.158). Los deseos de un monarca, concede Hobbes, pueden ser tan inestables como los de cualquier otro mortal, pero al menos cuentan con un principio de anclaje en el objeto de sus cuidados. La macroestructura estatal tiene una inmensa inercia propia y su suerte, como se vio, afecta de manera muy directa a los intereses de quien porta la corona. Hay, por así decir, un elemento naturalmente conservador y moderador en la configuración de la iniciativa monárquica. En una asamblea popular, en cambio, los componentes que determinan lo que finalmente habrá de resultar como voluntad soberana son muy variados, y vuelven más improbable la tan procurada constancia, que es condición para una coexistencia colectiva previsible y próspera. Sumado a la pluralidad y dispersión de pareceres que afecta a un cuerpo grande de personas a lo largo del tiempo, Hobbes advierte acerca del problema de que, cuando existen agrupamientos con visiones enfrentadas, cambios mínimos de parecer que sean propiciados por oradores seductores pueden hacer oscilar la balanza de las mayorías ocasionales con mucha frecuencia, logrando que se derogue hoy lo que se sancionó ayer. Y a esto hay que agregar, finalmente, el hecho muy habitual del poder de veto y de bloqueo que detentan las facciones, que suelen obstaculizar la acción mayoritaria por atender intereses privados, o por envidia (Hobbes, 1651/1983, 22, p. 323). Debe notarse que todo lo anterior, por lo demás, se traslada al cuerpo de servidores públicos, porque resta claridad y direccionalidad a los criterios generales con que los ministros y funcionarios deben interpretar las directivas políticas, cuando se aplican capilarmente a resolver las cuestiones concretas que son propias de la vida civil cotidiana. En la visión de Hobbes, en suma, la forma democrática, dificulta la unidad de propósito y la sinergia que debería animar a la maquinaria estatal, con un gradiente que, en última instancia, desemboca en la enfermedad de los ascárides, preámbulo para la guerra civil (Hobbes, 1651/1983, 29, p. 406). 


\section{Opiniones y consejos}

En el frente interno, el norte general del oficio del representante soberano es proveer un marco que haga a la tranquilidad y productividad del conjunto de la población. Ello implica, entre otras cosas, tener en claro cuáles son los problemas más usuales que acosan a las repúblicas, y disponer adecuadas medidas de prevención, o, eventualmente, de reforma. Una de las áreas más delicadas en la perspectiva hobbesiana es la del espacio público discursivo. La opinión, dice Hobbes, es un sentimiento subjetivo de certeza, a punto tal que se identifica con la conciencia moral, y es principio, por tanto, de la conducta de cada persona (Hobbes, 1651/1983, 7, p. 170). Dado que gobernar no es tanto forzar cuanto coordinar el accionar diverso de los integrantes de una multitud, la gestión soberana debe ocuparse de que las opiniones privadas no choquen excesivamente, ni entre sí ni contra el modo en el que los gobernantes valoran y determinan lo referente a la vida en común. La voluntad soberana, en última instancia, es la razón pública, que contiene y encauza el flujo de las opiniones privadas. Y el caso es que, según Hobbes, la mayoría de las opiniones que promueven un clima de desorden y sedición están asociadas, de una u otra forma, con una intención democratizante.

Significativamente, el extenso Leviatán no dedica una sola línea a considerar, siquiera como hipótesis, que alguien pueda proponerse, en actitud sediciosa, virar un régimen democrático a una monarquía. En cambio, resalta que nunca faltan hombres ambiciosos animados por la esperanza de que en un gobierno democrático tendrán una cuota de participación en el poder público de la que carecen en las monarquías, y que, por tanto, se ocupan de difundir argumentos especiosos favorables a sus intereses (Hobbes, 1651/1983, 11). Los tópicos más frecuentemente alegados por estos rebeldes, a menudo apoyados en argumentos de autoridad, sostienen que las democracias propician altos grados de libertad y de prosperidad. Pero nuestro filósofo advierte que tienen la precaución de omitir que, por un lado, la libertad que encomian los autores antiguos es la de las repúblicas y no la de los súbditos, que es siempre la misma, y está determinada por los permisos y silencios de la ley civil, mientras que, por el otro, al envidiar la prosperidad de repúblicas vecinas atribuyen, equivocadamente, la riqueza alcanzada al tipo de régimen, y no a su causa verdadera, y a menudo no advertida, que es una correcta y asentada relación entre la autoridad y la obediencia. Por lo demás, suele ocurrir que quienes difunden este tipo de opiniones, que cargan a la monarquía "con faltas que sólo se le pueden atribuir al enemigo" (Hobbes, $1651 / 1983,46$, p. 717) son, ellos mismos, personas muy populares, que pretenden hacer pasar sus opiniones y acciones privadas, así como las de quienes los siguen, como acciones y opiniones de todo el pueblo. Y a este tipo de situaciones es especialmente proclive el clima tumultuoso de las asambleas soberanas, en donde no existen garantías de la fidelidad pública de los hombres populares, quienes al arrogarse indebidamente la representación de todo el pueblo están incurriendo en "franca rebelión"» (Hobbes, 1651/1983, 29, p. 405).

Mencionemos, por último, una cuestión muy ligada $-\mathrm{y}$, en cierto modo, previa- a la del gobierno de las opiniones de los ciudadanos, así como a la de las opiniones que circulan en el interior de los equipos y cuadros funcionarios que sirven en la gestión estatal. Se trata de los consejos que podrían ayudar a la buena orientación de la voluntad del propio representante soberano. Aquí la consideración de las ventajas relativas de la monarquía respecto de la democracia observa un estrecho paralelo con las cuestiones ya vistas acerca de los intereses y la constancia. El monarca, dice Hobbes, está en situación de recibir buenos consejos y hacer un correcto uso de ellos porque los puede escuchar en soledad, eventualmente, también en secreto, y tiene libertad para seleccionar para ello a quien quiera, evitando así, en la medida de su propio criterio, darle voz y publicidad a quienes puedan beneficiarse con la creación de "publique trouble" (Hobbes, 1651/1983; 19 , p. 281, 30, p. 421). La asamblea democrática, en cambio, no puede, dada su naturaleza, deliberar en secreto. Tampoco podría, en principio, impedir la expresión de ninguna clase de opinión emitida por una persona integrante. Sin embargo, en los hechos, dada la dinámica que rige la construcción y la prevalencia de los discursos que acumulan poderío, allí sólo se escucha -dice Hobbes- a unos pocos que, por ser ricos o miembros de familias aristocráticas, no sólo presumen vanamente de ser sabios en asuntos políticos, sino que, por causa de su elevada posición, están incapacitados para prestar su acuerdo a cualquier opinión sensata que vaya en contra de sus prejuicios. La asamblea popular, en suma, no tiene cómo discriminar entre consejero y aconsejado; sus mayorías, por tanto, conformadas por la "gente del común" (common people), no pueden ser educadas por el soberano, es decir, orientadas hacia la recta opinión, porque lo constituyen. Pero sí, en cambio, pueden ser persuadidas y engañadas por las élites. Se replica, de este modo, el que entendemos como uno de los problemas básicos que preocupan a Hobbes, que es el de no poder establecer, una vez inaugurado lo estatal, una diferencia institucional clara que, a la vez que preserve la ficción de la condición autoral y fundante de

Una de las observaciones de Field acerca de lo inadecuado de adjudicar un vector favorable a la legitimidad del poder popular en la filosofía de Hobbes, precisamente, señala que el autor de Leviatán desenmascara el carácter elitista de los desafíos democratizantes, lo cual los invalida, por no ser abarcadores del conjunto, dado que el conjunto ya está representado por la voz resultante de toda la asamblea, o del monarca, como expresiones genuinamente populares. (Field, 2020). En el mismo sentido, parece oportuno mencionar aquí que el Artículo 22 de la Constitución Nacional Argentina ilustra casi al pie de la letra este recelo que siente Hobbes por los liderazgos sectoriales o facciosos que pretenden arrogarse la representación del conjunto: "El pueblo no delibera ni gobierna sino por medio de sus representantes y autoridades creadas por esta Constitución. Toda fuerza armada o reunión de personas que se atribuya los derechos del pueblo y peticione a nombre de éste, comete delito de sedición." 
cada hombre natural, mantenga a raya las expectativas de poder de las personas particulares que habitan como súbditas la república civil.

\section{Monarquía por institución}

Tenemos hasta aquí, entonces, una tensión evidente. Hobbes, por un lado, concede al impulso antropológico a la expansividad del poder y a la búsqueda de gloria de cada persona, junto con la admisión del tipo democrático de cuerpo soberano, una legitimidad formal que, sin embargo, se encarga de poner en cuestión, como se vio, en diferentes episodios del texto. Sin desmedro de las motivaciones contextuales que presionen sobre su escritura, pero que en cierto sentido son externas a la lógica filosófica de la doctrina, ${ }^{9}$ en lo que resta de estas notas nos interesa explorar algunas razones de orden conceptual que puedan dar cuenta de la ambivalencia mencionada.

Hobbes establece una diferencia entre la mera prudencia y el conocimiento propiamente filosófico (Hobbes, 1651/1983, 46, p. 701). La primera es una combinación equilibrada de experiencias y memoria. La filosofía, en cambio, si bien no se desentiende de los aspectos de su labor que puedan resultar útiles para la vida humana, se autoimpone además la exigencia de explicar las características de lo complejo por remisión a su modo de generación, conocida o conjeturada, a partir de elementos simples. Si la cuestión democrática en el Leviatán ha de tener una entidad más sustancial que la de una mera opinión prudencial, reforzada o no con ilustraciones históricas, el camino adecuado para iluminar las tensiones que venimos mencionando puede ser el de referirlas al origen de lo político postulado por la doctrina.$^{10}$

El Capítulo 29 de Leviatán es un buen lugar para buscar una conexión entre asuntos de eficacia y funcionamiento del poder estatal, de un lado, y consideraciones de orden más teórico, como las del comienzo conjetural, del otro. El título del capítulo, en efecto, anuncia el tratamiento de lo que, de un modo u otro, propicia el debilitamiento o la disolución de una república. Y la primera glosa marginal anticipa una respuesta resumida: "La disolución de las repúblicas proviene de su institución imperfecta" (Hobbes, 1651/1983, 29, p. 395).

Pues bien. Después de veintiocho capítulos que abundan sobre las diferentes derivaciones políticas y antipolíticas que pueden extraerse de la radical condición carente $-\mathrm{y}$, desde un punto de vista teológico, pecaminosa- de la naturaleza humana, el lector atento tiene derecho a (tiene el compromiso de) preguntar: ¿y qué podría ser, hablando con alguna precisión, una institución perfecta? Todo el capítulo 29 repasa imperfecciones de diseño y de manejo del artificio estatal, y no sólo conjeturadas, sino también corroboradas por la experiencia. Behemoth (1992), el tratado sobre las causas de la guerra civil inglesa, escrito unos años después de Leviatán, en 1668, casi que es una ilustración de los problemas que señala este capítulo. ${ }^{11}$ Los cuales, en líneas generales, siempre resultan de alguna combinación de ignorancia de los fundamentos verdaderos del Estado por parte de los actores vinculados con lo político, de tradiciones institucionales muy arraigadas pero inadecuadas, mala voluntad y vanidad. Todas estas son dificultades condicionantes que no podrían haber estado resueltas antes de que se hubiera instituido una república vigorosa y consistente, con plena capacidad pedagógica y, digamos, civilizatoria. Para usar la célebre expresión de Rousseau en El contrato social (1994), se diría que para la ocurrencia de una institución perfecta, que cortara el flujo sin tiempo de la brutal condición de naturaleza, el efecto debería haberse vuelto causa. Y aunque se admitiera, como lo hace Hobbes en el "Repaso y conclusión" (Hobbes, 1651/1983, Un repaso y conclusión, p. 740) que los principios normativos fundantes de una sana estatalidad son claros, sencillos y usualmente puestos en práctica por cualquier jefe de familia sensato, debe notarse que la institución de una república requiere de la confluencia simultánea de una multitud de opiniones y voluntades diversas. Es una diferencia de escala que desalienta toda esperanza de consenso espontáneo e inmediato respecto de las estructuras y prácticas políticas adecuadas. Por lo demás, en Leviatán, así como en los tratados políticos anteriores, Hobbes es muy claro al afirmar que los filósofos de la política, hasta el momento de la elaboración de su propia doctrina, no habían descargado su responsabilidad con el rigor conceptual que el asunto merece. Sin la aparición de una arquitectura verdaderamente científica como la que él presenta, desliza el filósofo, los edificios políticos estarán amenazados por una inestabilidad inescapable (Hobbes, 1651/1983, 30, p. 409).

En vista de lo anterior, resulta adecuado interpretar que por "institución" el comentario marginal mencionado no se refiere a la acción colectiva conjunta, narrada en el Capítulo 17, que da comienzo a la república en el momento cero, ya que en tal sentido ninguna asociación política podría haber tenido una institución perfecta.

Para una defensa, modo straussiano, del estudio de los textos de filosofía política en atención a la lógica interna de sus argumentos, Boucher (1984). Para una discusión sobre la conveniencia de diferenciar en la escritura de Hobbes entre intenciones de intervención política y de orden conceptual abstracto, cf. Springborg (2009).

10 Para una lectura que desvincula la visión de Hobbes acerca de la democracia respecto de su aparato teórico, y la percibe como mera expresión ideológica, cf. Hermosa Andújar (1998).

11 Thomaz Mastnak (2009) entiende que Hobbes en Behemoth no trata a la democracia como una forma política conceptualmente válida entre otras, sino como conjunto ideológico orientado a legitimar la destitución del régimen monárquico. La democracia, según esta lectura, es para Hobbes en Behemoth el emergente de los hijos irredentos del orgullo que se levantaron contra su rey. 
Se refiere, proponemos, al estado general de comprensión y contribución voluntaria para con el régimen vigente que, en cada configuración histórica concreta, anima a una cantidad crítica de agentes relevantes, tanto gobernantes cuanto servidores públicos y gobernados. O, dicho de otro modo: dado que ninguna manera de originarse en el tiempo una república puede carecer de (severas) imperfecciones, siempre existe, como condicionante basal, una componente que tiende a llevar las cosas hacia el debilitamiento y la disolución de todo Estado. Lo que puede volver más intensa dicha componente es la falta actual de disposición de los miembros de cada república para ratificar los fundamentos que, con más o menos conciencia, estén siendo acatados de hecho, así como para intentar reformar aquellos aspectos deficitarios del régimen que los están contrariando. En términos de la metáfora de la Introducción, se puede decir que siempre debería haber más personas en asumida posición de artífice, más allá de su condición social y jerarquía política, y menos en posición de materia bruta e indócil (Hobbes, 1651/1983, "Introducción", p. 118). Y entonces, dado que la institución perfecta no puede ser una figura del pasado, ni histórico ni conjetural, y que también es poco probable, dada su concepción antropológica pesimista, que Hobbes esté pensando en la realización impecable de un óptimo, es razonable tomarla como formulación de un modelo regulativo, de realización inalcanzable pero de intención irrenunciable. ${ }^{12}$ La institución perfecta, proponemos, es el norte modélico que debería orientar la gestión de todo representante soberano valiente y, notemos, libre de la influencia de consejeros interesados, una vez comprendida esa verdad de especulación que es el Leviatán. (Hobbes, 1651/1983, 31, p. 437). Cuanto mayor la conciencia y prevención de las imperfecciones que anticipa la teoría, menor la probabilidad de disolución.

Podemos reformular, entonces, el interrogante disparador para abundar sobre la línea de nuestra interpretación: ¿qué lugar asigna Hobbes al elemento democrático, tanto en el origen ficcional cuanto en la actualidad relativamente defectuosa de cualquier república, y aún en el modelo puro? ¿Cómo debería tomarlo en cuenta el demiurgo gobernante (persona natural o asamblea) que haya leído y comprendido a Hobbes, para el cual la materia a (re)informar ya no sería el caos originario del Capítulo 13 sino esa combinación de facticidad y módica validez gracias a la cual se sostiene, mal que bien, la república sublunar, efectivamente acaecida, que le ha tocado en suerte? Por una parte, desde el punto de vista evaluativo de Hobbes, el régimen democrático, vimos, es inconveniente como actualidad, temible como destino y, como ideología declamada, bandera asidua de acoso a las monarquías establecidas. Pero, por la otra, es una figura de la cual la dimensión teórico-ficcional no puede prescindir. La participación activa de cada persona en la construcción consciente de lo político es la aplicación más inmediata de la segunda ley de naturaleza. Esta norma racional, que vela por la autopreservación, ordena a cada cual no resignar ningún derecho natural que cada semejante no se muestre dispuesto a resignar. El espíritu de cautelosa reciprocidad de esta norma racional parece mucho mejor expresado si el detalle del contrato originario fuera imaginado como diciendo "cada uno de nosotros, los autorizantes, renuncia a la plenitud de su libertad natural, pero para pasar a formar parte del naturalmente libre cuerpo soberano" que si dijera "cada uno de nosotros autoriza a una única persona natural, para que de ahora en más, investida con todo nuestro poder conjunto, porte la persona de la república y nos gobierne sin límites positivamente establecidos." ${ }^{13}$ De esta manera, la república por institución con forma democrática de soberanía aparece, en principio, como la menos abrupta de las transiciones en ese pasaje conjetural que va desde el derecho natural de cada uno a toda cosa y cuerpo, hacia la libertad civil, en la que cada súbdito es propietario legítimo sólo de los bienes y acciones que asigna y permite arbitrariamente la voluntad soberana. ${ }^{14} \mathrm{Si}$ bien, ya como ciudadana cada persona privada deberá guiarse por la ley civil, al menos, en la asamblea, en cambio, como parte del sistema soberano sigue siendo responsable in foro interno del modo en que se las ve con la ley natural, que también es voz divina.

Hay un pasaje del Capítulo 22, relativamente lateral, que viene a cuento de nuestra argumentación porque establece un puente interesante entre el talante democrático y la consideración de lo monárquico. Dice allí Hobbes, hablando de la forma de gobierno de un territorio colonizado o conquistado, que

aunque todo hombre (cuando puede estar presente) por naturaleza desea participar en el gobierno, allí donde no puede estar presente se siente inclinado por naturaleza a confiar el gobierno del interés común a una forma monárquica más que popular de gobierno. (Hobbes, 1651/1983, 22, p. 317).

12 Coincidimos con Tuck (2004) en que un aspecto de la escritura hobbesiana es claramente modelizante, y en ese sentido, utópico. Pero diferimos con este autor, como se verá a continuación, cuando entiende que el proyecto hobbesiano es anticipación de las distopías contemporáneas, porque ofrece garantías de confort y seguridad al precio de la anulación de la dignidad del individuo.

13 Runciman (2012) considera que la diferencia entre la autorización que ejerce, en hipótesis, cada individuo y la representación que ejerce el soberano respecto sólo del cuerpo político así constituido tiene en Hobbes la intención de conciliar sus recelos para con la forma democrática de gobierno, al tiempo de habilitar una cierta forma de representatividad política propiamente moderna, ya liberada de las cargas medievales teológicas y corporativas.

14 Jakonen (2016), enfatizando la relevancia del momento democrático originario, entiende que la figura "pueblo" es, en Hobbes, la primera entidad propiamente política, por lo ficcional y por lo pública, que encarna la mediación entre la multitud desunida y caótica, de un lado, y la soberanía, del otro. El recelo de Hobbes para con lo democrático, según este estudioso, podría ser un antecedente relevante para la conceptualización de la cuestión contemporánea del populismo. 
Uniendo esto con lo anterior, se puede apreciar que, para la doctrina de Leviatán, lo democrático, como elemento inicial, no sólo es necesario por exigencia teórica, sino también proclive, por inclinación antropológica. ¿Cómo conciliar esta apreciación, entonces, con los señalamientos, igualmente apoyados en la teoría, de que, como, forma política, la democracia es de comienzo histórico imposible ${ }^{15} \mathrm{y}$ de actualidad inconveniente $\mathrm{e}$ inestable ${ }^{16}$ La respuesta especulativa que queremos ofrecer aquí es que Hobbes podría estar proponiendo un modelo de monarquía (como si) por institución. Una forma estatal que, de un lado, tenga el vigor, estabilidad y unicidad de propósito y criterio que le daría una soberanía ejercida por una persona natural, adulta, responsable y comprometida existencial -y tal vez, hasta vanidosamente- con la salus de la república, pero que, del otro, estimule en todos sus integrantes una actitud de lealtad afín a la que sería propia de alguien que participó activamente en el diseño y realización de una "institución perfecta." Un Estado monárquico en el que, por virtud de un funcionamiento virtuoso en los diferentes espacios de interacción pública y privada, cada persona ciudadana se autoperciba como si hubiese salido de la condición de naturaleza gracias a la extroversión de su confianza en la voluntad y en el conocimiento práctico de sus semejantes. ${ }^{17}$

El orden monárquico, como se vio, no puede contener, por sí solo, el deseo natural de todo súbdito a procurar a toda costa el dominio de cada otro, $\mathrm{y}$, aunque bastante entendible como tipo resultante de un acto de conquista, es impensable, en lo fáctico, como forma inicial voluntariamente elegida por los miembros de una multitud que se hallen libres de amenaza externa. ${ }^{18} \mathrm{~A}$ efectos de dar algún curso a los impulsos elementales que trajinan en la búsqueda incesante de reconocimiento y de poder tras poder, y para no caer en la ingenuidad de confiar excesivamente en el carácter amigable que aconsejan las maneras, el esquema hobbesiano, creemos, dispone de tres vías de, digámoslo así, freudianamente, sublimación. ${ }^{19}$ Por el lado privado, está la actividad económica en general, que, en los comienzos de la modernidad, adopta una dinámica que, si bien competitiva, ya no es explícitamente violenta (Macpherson, 1962). Competir por los bienes materiales y financieros es una manera civilmente aceptable de pujar por el dominio, y también de contribuir al vigor y la riqueza de la república. En línea con este afán posesivo está también el orden de los sistemas (Hobbes 1651/1983, 22), esas asociaciones civiles en los cuales, bajo la supervisión pacificante de la ley civil, acontecen diferentes tipos de liderazgo, antagonismos internos, alianzas, retóricas proselitistas, votaciones, discusión de metas y de estrategias, etc. (Rilla, 2017). Y por el lado público, está el servicio estatal, ejercido por ministros, jueces y demás funcionarios. Todas estas personas, que, por una parte, están determinadas a ejercer un poder delegado con normativas explícitas que no se originaron en su querer individual (uso privado de la razón, lo llamará Kant), tienen a su disposición, por la otra, un espacio amplio para el despliegue de sus respectivas facultades judicativas. Hobbes, hablando de la tarea judicial, dice que las sentencias correctas son, precisamente, aquellas que, a la vez que no permiten que primen la opinión y el gusto particular de quien las dicta y manda ejecutar, resuelven el caso concreto interpretando el auténtico espíritu de la voluntad soberana que ha proclamado la ley civil, en una muestra virtuosa de aquella rama de la justicia natural que se define como "fidelidad" (Hobbes, 1651/1983, 26, p. 353). Se daría así en el servicio oficial el caso inverso al que se vio en la asamblea popular: la superposición de instancias de representación (a saber, un funcionario munido de autoridad circunscripta, que representa al ministro, que representa al soberano, quien a su vez porta la persona de la república) robustece el sentido comunitario, y, por vía de la fidelidad (la misma que no cabe esperar, recordemos, de los oradores ambiciosos de la democracia), concilia el vector descendente del mando con la dirección ascendente de la participación. $^{20}$

15 La imposibilidad de la república por institución como forma histórica es, entendemos, el presupuesto que subyace a la llamativa afirmación del "Repaso y conclusión", que postula que no hay registro histórico de prácticamente ninguna república que pueda justificar su origen en conciencia (Hobbes, 1651/1983, Un repaso y conclusión, p. 737).

16 Coincidimos, en líneas generales, con los que tematizan la compleja, y a veces, no del todo acabada, tarea de conciliación de tendencias divergentes que encara Hobbes en su Leviatán. Runciman (2012), por ejemplo, habla de la intención paradójica de Hobbes por "cuadrar el círculo", haciendo a los representantes soberanos a la vez dependientes e independientes del derecho de participación y demanda de los ciudadanos; Stauffer (2018), por su parte, advierte que Hobbes debe postular un momento quasidemocrátrico en el origen, para luego pugnar por su inadvertido desvanecimiento, y absorción de su vitalidad en la soberanía monárquica; Field (2020), propone como el "problema político fundamental" de Hobbes la necesidad de conceder participación ciudadana sin exponer al soberano a la desestabilización proveniente de la ambición de las facciones, que no han conciliado con la voluntad del resto de los habitantes. La solución que esta autora encuentra en Hobbes, con la cual en parte concordamos, es la de un "igualitarismo represivo", que fragmenta el poderío societal a fines de diluirlo y atomizarlo.

17 Para un estudio que resalta la centralidad de la confianza como fundamento de legitimidad en Hobbes, aunque derivada del compromiso de vida y libertad asumido por un soberano conquistador, cf. Baumgold (2013). Por su parte, observa Madanes (2020) que la actitud de las personas populares que buscan torcer el curso de las deliberaciones con opiniones y doctrinas especiosas es una manera de violar la lógica, basada en la confianza recíproca, de toda asamblea, la cual, como enfatiza Hobbes, es el respeto por la regla de las mayorías. En este sentido, creemos que Hobbes está tratando de hacerle ver a la gente del común que, en una asamblea soberana, ellos serían convidados de piedra.

18 Para la relevancia y simultánea limitación de los aportes de la figura de la adquisición para la validez del modelo hobbesiano Galimidi (2004). También Hoekstra (2004), quien señala que en Hobbes la soberanía de jure nunca puede preceder a la instauración de facto.

19 Sobre las limitaciones que la doctrina de Hobbes impone al poder eventualmente hegemonizante de la soberanía, a efectos de conciliar coerción con una inextinguible pluralidad, cf. Fernández Peychaux (2015).

20 Kahn y Brennan-Marquez (2014) proponen que la participación democrática en la construcción del marco legal, a la que Hobbes se resiste, se ve, sin embargo, reconocida en la necesaria colaboración que el súbdito presta a la narrativa que propone un juez cuando, en representación del poder soberano, fundamenta adecuadamente sus fallos. Rosler (2010), por su parte, entiende que la lógica hobbesiana de la representación, que desnaturaliza para bien, (porque las seculariza) las relaciones intersubjetivas y las vuelve propiamente políticas, es una manera de reivindicar la soberanía 


\section{Conclusión}

En la Epístola Dedicatoria a Sir Francis Godolphin, Hobbes teme por la recepción no ecuánime que pueda tener su libro, dado que el mundo, dice, está agitado por quienes desde un extremo, reclaman "demasiada libertad" y se enfrentan con los que, desde el otro, exigen "demasiada autoridad" (Hobbes, 1651/1983, Epístola dedicatoria a Francis Godolphin, p. 113). Y el asunto del Leviatán, precisamente, si se atiende a la celebérrima referencia bíblica del Libro de Job que corona la portada, es el problema de cómo construir un artificio político que pueda perdurar en el tiempo, siendo que su estabilidad se encuentra siempre amenazada por la soberbia constitutiva de los individuos humanos que fungen como gobernantes y gobernados. Ahora claro, el equilibrio teórico buscado, igual que sucedía con las virtudes aristotélicas, no puede ser un cálculo aritmético, sino que debe respetar lo específico de la cosa estudiada. En nuestro recorrido, hemos tratado de mostrar los fundamentos del recelo de Hobbes para con el afán de participación en el poder político como un intento de responder al mencionado problema del equilibrio. Vemos en el Leviatán la presentación de una constelación político-social que, a la vez que precavida respecto de los desbordes de la voluntad de poder, se vale de este impulso elemental para vitalizar, y legitimar, tanto la ficción del momento excepcional fundacional, cuanto el funcionamiento efectivo de los diversos sectores de la convivencia pacífica normal i.e. economía, sociedades civiles y funcionariado. El ideal modélico de Hobbes sería así una especie de monarquía absoluta (como) por institución, con tanto margen para la expansividad del poder subjetivo de los súbditos como sea posible, y tanta coacción y soledad soberana como sea necesario. La historia posterior habría de tomar su propuesta como un oxymoron, y pugnaría por incluir, como fundamento de la legitimidad soberana, alguna forma de contrapeso parlamentario y constitucional. ${ }^{21}$

\section{Bibliografía}

Abizadeh, Arash (2018). Hobbes and the two faces of ethics [Hobbes y los dos rostros de la ética]. Cambridge University. doi: https://doi.org/10.1017/9781108277310

Airaksinen, Timo (2019). Thomas Hobbes on intentionality, desire, and happiness [Hobbes sobre intencionalidad, deseo y felicidad], en su Vagaries of desire: A collection of philosophical essays. Brill. doi: https://doi. org/10.1163/9789004410305

Baumgold, Deborah (2013). "Trust" in Hobbes's political thought [“Confianza” en el pensamiento político de Hobbes]. Political Theory, 41(6), 838-855. doi: https://doi.org/10.1177/0090591713499764

Boucher, David (1984). The denial of perennial problems [La negación de los problemas perennes]. Interpretation, 12(23), 287-300.

Collins, Jeffrey (2005). The allegiance of Thomas Hobbes [La lealtad de Thomas Hobbes]. Oxford University.

Constitución de la Nación Argentina [Const.]. Ley No 24.430. Art. 22. Enero 3 de 1995.

Crepell, Ingrid (2003). The democratic element in Hobbes's Behemoth [El elemento democrático en el Behemoth de Hobbes]. Filozofski vestnik, 24 (2), 17-35.

Desclée de Brouwer (1975). Génesis.

Dotti, Jorge Eugenio (1989). El Hobbes de Schmitt. Cuadernos de Filosofia, 32, 57-69.

Dotti, Jorge Eugenio (2011). La cuadratura del círculo. La Constitución argentina como testimonio de la imposible normativización de lo político. En Dotti, Jorge Eugenio, Las vetas del texto (pp. 165-246). Las cuarenta.

Dotti, Jorge Eugenio (2014). La representación teológico-política en Carl Schmitt. Avatares filosóficos, 1, 27- 54.

Douglass, Robin (2018). Authorization and Representation before Leviathan. [Autorización y representación antes del Leviatán]. Hobbes Studies, 3(11), 30-47. doi: https://doi.org/10.1163/18750257-03101003

Dyzenhaus, David (2001). Hobbes and the Legitimacy of Law [Hobbes y la legitimidad del derecho]. Law and Philosophy, 20, 461-498. doi: https://doi.org/10.2307/3505220

Fernandez Peychaux, Diego (2015). El desafío de Thomas Hobbes: unidad y pluralismo. Bajo Palabra. Revista de Filosofía. 10, 95-106. doi: https://doi.org/10.15366/bp2015.10.007

Field, Sandra Leonie (2020). Potentia. Hobbes and Spinoza on power and popular politics. Potentia. [Hobbes y Spinoza acerca del poder y la política popular]. Oxford University. doi: https://doi.org/10.1093/oso/9780197528242.001.0001

Foisneau, Luc (2000). Hobbes et la toute-puissance de Dieu [Hobbes y la omnipotencia de Dios.] Universitaires de France. doi: https://doi.org/10.3917/puf.fois.2000.01

Foisneau, Luc (2014). Hobbes on desire and happiness [Sobre el deseo y la felicidad en Hobbes], Homo Oeconomicus, $31(4), 479-489$.

Galimidi, José Luis (2004). Leviatán conquistador. Reverencia y legitimidad en la filosofía politica de Thomas Hobbes. Homo Sapiens.

del Estado frente a las tendencias anarquizantes del republicanismo tardoaristocrático.

21 Para un estudio que analiza la persistencia paradojal de las tensiones que introduce la coexistencia de los vectores de soberanía popular y decisividad soberana en el orden institucional de la Argentina contemporánea, cf. Dotti (2011). 
Hermosa Andújar, Antonio (1998). La doctrina de las formas de Estado en Hobbes. Estudios políticos, 18, 53-60. doi: https://doi.org/10.22201/fcpys.24484903e.1998.18.37192

Hobbes, Thomas (1983). Leviatán, o la materia, forma y poder de una república eclesiástica y civil. (A. Escohotado, Trad). Editora Nacional. (Trabajo original publicado en 1651).

Hobbes, Thomas (1992). Behemoth (M. A. Rodilla, Trad.). Tecnos (Trabajo original publicado en 1668).

Hoekstra, Kinch (2004). The de facto turn in Hobbes's political philosophy [El giro de facto en la filosofía política de Hobbes]. En T. Sorell y L. Foisneau (Eds.), Leviathan after 350 years (pp. 33-74). Oxford University. doi: https://doi. org/10.1093/acprof:oso/9780199264612.003.0003

Hoekstra, Kinch (2006). A lion in the house: Hobbes and democracy [Un león en la casa: Hobbes y la democracia]. En A.Brett y J. Tully (Eds), Rethinking the foundations of modern political thought (pp. 191-218). Cambridge University. doi: https://doi.org/10.1017/CBO9780511618376.012

Jakonen, Mikko (2016). Needed but unwanted. Thomas Hobbes's warnings on the dangers of multitude, populism, and democracy [Necesarios pero no queridos. Las advertencias de Hobbes acerca de los peligros de la multitud, el populismo y la democracia]. Las Torres de Lucca, 9, 89-118.

Kahn, Paul y Brennan-Marquez, Kiel (2014). Status and democratic self-authorship [El status y la auto-autoría democrática]. William and Mary Law Review. 56(1), 115-179.

Kapust, Daniel y Turner, Brandon (2013). Democratic gentlemen and the lust for mastery: status, ambition, and the Language of liberty in Hobbes's political thought [Los caballeros democráticos y el deseo de señorío: status, ambición y el lenguaje de la libertad en el pensamiento político de Hobbes]. Political Theory, 41(4), 648- 675. doi: https://doi. org/10.1177/0090591713485445

Lloyd, Sharon. (1992). Ideals as Interests in Hobbes's Leviathan [Los ideales como intereses en el Leviatán de Hobbes]. Cambridge University.

Lund, William (2003). Neither "Behemoth" nor "Leviathan": explaining Hobbes's illiberal politics [Ni "Behemoth" ni "Leviatán": explicando la política no liberal de Hobbes]. Filozofski vestnik, 24(2), 59-83.

Macpherson, Crawford (1962). The political theory of possessive individualism [La teoría política del individualismo posesivo]. Oxford University.

Madanes, Leiser (2020). Democracia y regla de la mayoría en Thomas Hobbes. En Andrés Di Leo Razuk (Comp.), Tradición y modernidad de la teología política (pp. 167-182). Colihue.

Martel, James (2007). Subverting the Leviathan: reading Hobbes as a radical democrat. [Subvirtiendo el Leviatán: leer a Hobbes como un demócrata radical]. Columbia University. doi: https://doi.org/10.7312/mart13984

Mastnak, Thomaz (2009). Godly democracy [Democracia divina]. En Masnak, Thomaz (Ed.), Thomas Hobbes's Behemoth. Religion and democracy (pp. 210-240). Imprint Academic,

Pettit, Philip (2008). Made with Words. Hobbes on language, mind, and politics. [Hecho con palabras. Hobbes sobre el lenguaje, la mente y la política]. Princeton University. doi: https://doi.org/10.1515/9781400828227

Pocock, John Greville Agard (1971). Time, history, and eschatology in the thought of Thomas Hobbes [Tiempo, historia y escatología en el pensamiento de Thomas Hobbes] En Politics, language, and time (pp. 148-201). Atheneum.

Rilla, Jerónimo (2017). El reverso de las corporaciones hobbesianas. Anales del Seminario de HIstoria de la Filosofía, 34(2), 389-409. doi: https://doi.org/10.5209/ASHF.56107

Rosler, Andrés (2010). El enemigo de la República: Hobbes y la soberanía del Estado. En Thomas Hobbes, Elementos filosóficos del ciudadano (pp. 9-101; A. Rosler, Trad.). Hydra.

Rousseau, Jean Jacques (1994). Del contrato social o Principios del derecho político (M. Armiño, Trad.). Alianza (Trabajo original publicado en 1762)

Rutherford, Donald (2003). In pursuit of happiness: Hobbes's new science of ethics. [En busca de la felicidad: la nueva ciencia de la ética de Hobbes]. Philosophical Topics, 31(1-2), 369-393. doi: https://doi.org/10.5840/philtopics2003311/26

Runciman, David (2012). Hobbes's theory of representation: anti-democratic or proto-democratic? [La teoría de la representación de Hobbes: ¿antidemocrática o protodemocrática?]. En I. Schapiro, S. C. Strokes, E. Jean Wood y A. S. Kirshner (Eds), Political Representation (pp. 59-83). Cambridge University.

Skinner, Quentin (2008). Hobbes and republican liberty [Hobbes y la libertad republicana]. Cambridge University.

Slomp, Gabriella (2007). Hobbes on glory and civil strife [Hobbes sobre la gloria y la lucha política]. En P. Springborg, (Ed.), The Cambridge companion to Hobbes's Leviathan (pp. 181-198). Cambridge University. doi: https://doi. org/10.1017/CCOL0521836670.008

Sorell, Tom (2004). The burdensome freedom of sovereigns [La gravosa libertad de los soberanos]. En T. Sorell y L. Foisneau (Eds.), Leviathan after 350 years (pp. 183-196). Oxford University. doi: https://doi.org/10.1093/ acprof:oso/9780199264612.003.0009

Springborg (2009). The paradoxical Hobbes: a critical response to the Hobbes Symposium [El Hobbes paradójico: una respuesta crítica al Simposio de Hobbes]. Political Theory 37 (5): 676 - 688. doi: 10.1177/0090591709340140

Stauffer, Devin (2018). Hobbes's kingdom of light [El reino de la luz de Hobbes]. The University of Chicago. doi: https:// doi.org/10.7208/chicago/9780226553061.001.0001

Strauss, Leo (1936). The political philosophy of Hobbes. Its basis and genesis [La filosofía política de Hobbes. Su base y génesis.]. Oxford Clarendon. 
Tarlton, Charles (1978). The creation and maintenance of Government. A neglected dimension of Hobbes's Leviathan [La creación y mantenimiento del gobierno. Una dimensión olvidada del Leviatán de Hobbes]. Political Studies, 29, 307-327. doi: https://doi.org/10.1111/j.1467-9248.1978.tb01296.x

Taylor, A. E. (1965). The ethical doctrine of Hobbes [La doctrina ética de Hobbes]. En K. C. Brown (Ed.) Hobbes Studies (pp. 9-36). Harvard University.

Tuck, Richard (2004). The utopianism of Leviathan [El utopismo del Leviatán]. En T. Sorell y L Foisneau, Leviathan after 350 years (pp. 125-138). Oxford University. doi: https://doi.org/10.1093/acprof:oso/9780199264612.003.0006

Tuck, Richard (2006). Hobbes and democracy [Hobbes y la democracia] En A. Brett y J. Tully (Eds) Rethinking the foundations of modern political thought (pp. 171-190). Cambridge University. doi: https://doi.org/10.1017/ CBO9780511618376.011

Tuck, Richard (2015). The sleeping sovereign: the invention of modern democracy [El soberano dormido: la invención de la democracia moderna]. Cambridge University. doi: https://doi.org/10.1017/CBO9781316417782

Viux, Lars (2012). Hobbes on civic liberty and the rule of law [Hobbes sobre la libertad civil y el estado de derecho]. En D. Dyzenhaus y T. Poole (Eds.), Hobbes and the Law (pp. 145-64). Cambridge University.

Walzer, Michael (1993). Las esferas de la justicia. Fondo de Cultura Económica.

Warrender, Howard (1957). The political philosophy of Hobbes. His theory of obligation [La filosofía política de Hobbes. Su teoría de la obligación]. Oxford University.

Wolin, Sheldon (1990), Hobbes and the culture of despotism [Hobbes y la cultura del despotismo]. En M. Dietz (Ed.). Thomas Hobbes and Political Theory (pp. 9-36). University of Kansas. doi: https://doi.org/10.2307/j.ctv1p2gmg6.7 